\title{
Re-viewing the Fruits of the Mango Tree: From Linguistic Translation to Cultural Adaptation
}

\section{G. K. Subbarayudu}

\begin{abstract}
Using the exchange of the review and response of the recent translation of the classic Telugu play, 'Kanyasulkam' by Vijayasree and Vijay Kumar, this paper attempts to demonstrate the crying need for a very sensitive approach towards reviewing of translated works that would draw out the best from the translator's and the original writer's efforts to preserve the cultural uniqueness and specificity through semantic-cultural adaptation.
\end{abstract}

When the Telugu Classic Play, Kanyasulkam was translated by Vijayasree and Vijay Kumar and published by The Book Review Literary Trust in 2002, the weekly literary review page 'Vividha' of the Telugu daily Andhra Jyothi carried a scathing review. Subsequently it also published the translators' rejoinder, the angry and authoritative reviewer's response and some other interventions. What was turning into a debate which could have salutary impact on the practice of review/criticism in Telugu was abruptly closed by the newspaper with a rather dismissive last word by the original reviewer. I made an attempt to play Sydney to Stephen Gosson but Pennepalli Gopalakrishna would have none of it. His contentions, some of which were substantial, were

(a) that the dialectal differences and nuances were not handled suitably by the translators,

(b) that they seemed to be under the 'charm'ing influence of $\mathrm{N}$. T. Rama Rao's movie which was itself a pathetic failure,

(c) that there were innumerable and unpardonable mistakes,

(d) that the translators in this instance English teachers by profession, were unfit to undertake a task of such magnitude 
and that from the choice of text/edition/version to the choice of words/expressions the translation was a weave of woeful mistakes.

And Pennepalli's major assertion was

(e) that translations of such classical works ought to be done by eminent Telugu scholars whose literary-historical, cultural and dialectal credentials were impeccable, in collaboration with English/American translators whose authority over English and its dialects/variants would enable them to suggest appropriate equivalents.

This dogma was largely satisfied by Velcheru Narayana Rao's Girls for Sale (Indiana University Press, 2007) who blended scholarly pedigree with keen, friendly advice of several academics and comrades, not least among them, David Shulman. Velcheru's translation claims that much was done to give the language a colloquial ease ('bunch of bullshit,' p.8); but Velcheru makes it abundantly clear in his 'Note on Translation and Transliteration' that he, 'made no effort to reflect the dialect variations in [his] translation' (Rao 2007: xv).

Pennepalli's failsafe mantra for translation having been given more than its due, and Velcheru's very title for the classic, echoing Girisam, turning a prize issue for debates on semantic-social=cultural translatability (Girisam says 'yeeDaevainaa,' "selling girls" anagaa kanyaasulkam, dammit! Yentha maathramuu koodadanDi' (Whatever the age, selling girls, that is kanyasulkam, damiit! Should not be...) (Apparao 1007: 40), and the issue of dialectal variations proving rather obdurate, the chief questions that arise are:

(i) Is literary translation possible at all?

(ii) What role may a reviewer play in the translational project?

(iii) Is the reviewer-critic entitled to vitriolic views in defence of the venerable 'original text'? 
Re-viewing the Fruits of the Mango Tree:

From Linguistic Translation to Cultural Adaptation

The basic question of translatability and the practice of translation continue to engage the attention of academics because no easy answers exist. But the practitioner will not, of course, stop for theoretical discussions to resolve themselves before he may reclaim his passion. The role of the reviewer, then perhaps, assumes critical primacy.

That cognitive-perceptual reciprocity exists in some measure or the other, there is ample proof in the incremental corpus of translations from and into various languages. In one sense translation as well as original text are always already indistinguishable, as Probal Dasgupta pointed out in his presentation, "A Roadmap to Civilianisation" at the ACLALS Triennial in 2004. His submission was that Language per se was just one unique form of behaviour, and languages were different manifestations of the unique behavior, therefore what was manifest in one language was already potentially available in Language as its matrix i.e., 'in a permanent state of translation,' and that 'cultures are in a state of translation...,' (Vijayasree et al 2007: 114). This is a sound theoretical position but has little practical value for, say a Szymborska whose rich Polish poetry cannot thrive but for the English interventions of translators such as Clare Cavanagh and Stanislav Baranczak. Indeed my own dream project is a Telugu rendering of Szymborska via the English version; and I do not at all feel complacent and reassured by Probal Dasgupta's theoretical position: 'There is, formally, only one human language with various words attached that makes it look as if we speak different languages,' (Vijayasree et al 2007: 118). That would be less than fair to a non-English-knowing Telugu readership which would likely find it irresponsible on the part of academics to theorize away great literature by a nice derangement of ideas over practices.

If between Probal Dasgupta's theoretical sophistication and Velcheru's culturally dubious internationalization ('Girls for Sale' smells strongly of flesh-trade, slave trade and promptly catches the attention of the countless in and outside India afflicted by a Katherine 
Mayo-Louis Malle syndrome) and the reviewer-critic Pennepalli's vitriolic views in defence of the venerable and sacrosanct 'original text', if the avid reader's eagerness for the variety of world literatures is doomed to dissatisfaction and disaffection, then the translational project itself is called into question. For the theorist, the practitioner and the reviewer are all taking the readers on a roller-coaster ride from which they may emerge not a little dazed if not entirely bilious in their mouths. Instead of translation, would it be more useful to think and practice adaptation? Would that provide a more suitable platform from which to practice the rendering of texts from one language into others? Would that be a linguistic act or a cultural performance which would accept as axiomatic cultural translatability through cognition, than linguistic untranslatability owing to perceptual difference?

Several months after the debate on Kanyasulkam's translation was peremptorily closed by Andhra Jyothi, its 'Vividha' section carried an article by Afsar on the growth of translated work from Telugu into English in the last decade or so. Afsar offered a useful sketch of the developments, mentioned the names of some of the well-known practitioners, their views/visions, and the prospect for ProjectTranslation as a cultural responsibility of Telugu literati. Afsar's admiration of the Katha-Prize-Winning duo, Uma and Sridhar shone through the article, and it was edifying to note that a difficult task well-performed was earning deserved recognition without the usual objections about the crucial significance of what was lost in transmission, and the consequent damage to Telugu literature.

What happened next was truly damaging to Telugu literature, translation, and critical review. 'Vividha' carried a vituperative essay by Prasad in response to Afsar's perhaps overstated enthusiasm. Prasad ridiculed the vision of the translators Afsar had lauded; he introduced and condemned publishing houses' sales-driven nomenclatural practices, holding the translators obliquely responsible for 'unethical' practices; in defence of which allegations he produced correspondence between Ranganayakamma, a stalwart Telugu writer and the publishers. 
The stalwart's ire was refracted towards the translators who, one may surmise, had little to do with the publisher's sales strategies. In the process the discussion turned disturbingly camp, and Telugu literary review/ criticism slipped, grievously, a notch or two if not more. Critical review had lost ground to personalities and, preferences, not different from Pennepalli's caustic and cultish remarks. And the loser was Telugu literature and its translation, not any individual writer or translator whose labour of love is beyond issue.

Velcheru Narayana Rao had translated 100 padams of the $15^{\text {th }}$ century Telugu poet Taallapaaka Anamaachaarya, a bhakta of Lord Venkateswara as God on the Hill (2005). I went eagerly to a padam I like as much for the bhaava as for the beautiful rendition of M. S. Subbulakshmi: 'enta maatramunan/ evvaru talacina/ anta maatrame/ neevuu', translated as 'You're just about as much as any one imagines you to be.' Is translation solely a semantic act, or a cultural act that must make some attempt, at least a gesture towards the sounds, cadences, rhythms and other imaginative materials of the language translated? For instance, the first and second lines of the padam scan into a structure of 8 maatraas (measures), resolving into 7 beats in $\mathrm{M}$. S. Subbulakshmi's rendition (which I take as standard for this padam). This attribute can be usefully introduced into the English translation by using English vowel-lengths in place of English stress, or even combining the two. Then the first line could read 'Soo much a(e)s any/ one 'ma(e)gined yu:h, Su:ch to him / will bee yu:h.' This is not to detract from Velcheru's semantic translational method which yielded 'You're just about as much as anyone imagines you to be,' but to add a cultural element to the translational project, a touch of salt to the semantic, almost paraphrastic, blandness.

In the course of attempting such "value-additions", I blundered with the semantics of one line. In my musical reverie, I had misheard 'pindanthee nippadi' in the next line, a simile, 'anta raantaramu llenchee chooda II pindantE nippadi I ennaatLoo II' and did not take time out to check the padam in print. The horrendous misquoting, and misreading 
still makes me cringe; but the struggle with the expression 'pindanthee nippadi' (or 'nippaTi') continues.

'Nippadi' (or 'nippaTi') is said to be a well-used term in certain regions of South India as the equivalent of 'rotii' or 'rotte' (an unleavened bread). Not being aware to what extent 'raagi' or 'jonna' ('makkai') is used in South India as food, the region being chiefly a rice-growing one, I could not help puzzling over the kind of 'rotte' the padam referred to. What sort of 'rotte' could the rice-dependent folk prepare? The 'attu' made/burnt directly on 'nippu' (Fire), should then be a flattened bit of batter/dough prepared on fire, rather like a tandoori roti, or a phulka that is burnt directly on fire; nippu + attu $\longrightarrow$ nippattu. Rice-flour is either coarse, grainy or soft powder -- neither can be made into batter of required consistency for turning out flattened pieces of dough that can be burnt directly on fire, unless the flour is first steamed sufficiently to soften and give it an adhesive quality. The labour involved, I think, is too time-consuming for working class people rendering daily use nearly impossible. Was, then, 'nippattu' a festival/ occasional preparation?

I am uneasy with this expression for yet another reason: in the common saying 'pindi koddii rotte' is the semantic thrust quantitative or qualitative? That is, an ambiguity needs to be resolved if Velcheru's translation is to be sustained. The expression can mean 'as much as' and 'as good as' - as much as the quantity of dough available, or as good as the quality of the dough. Velcheru's line 'You're just about as much as anyone imagines you to be' goes for quantity. There is another kind of preparation called 'attu' (as in 'pesarattu', 'bobbattu') which is a large pan cake which, too, adds to the ambiguity of 'nippu+attu—nippattu'. Again, batter that is allowed to sour/ferment a little is steamed to make 'rotte/attu' (as in 'minapa rotte', 'dibba rotte' and 'minapattu'). Which practice does the padam refer to? Fifteenth century social economy and culture-based criticism and review becomes necessary here, I suppose.

Now time for an overview. While there is so much to study carefully, what good purpose has the reviewer in 'Vividha,' including 
the present writer served? 'Bheebhatsam, Bhayaanakam,' roared Pennepalli in anger about the 2002 translation of Kanyasulkam, and later asserted that his anger was 'sadaagraham,' righteous indignation. Is righteous indignation good criticism ('Sadaagrham Vimarsayaena'), asked yours truly. Afsar eulogized the contribution of our colleagues, while Prasad brought in the acerbic -tone of Ranganayakamma to score pugilistic points. The translator, meanwhile, and the importance of translation work takes a back seat, yielding place to personal ideologies and agendas which can only vitiate the critical climate and paralyse the multilingual aspirations of literary work. Between the theory of Probal Dasgupta and the critical outlook of the 'Vividha' page, translation-practice is well on its way to suffering a stroke. On the other hand, if forced and commissioned translations and unconditionally eulogistic reviews of writers' work alone are taken into account, the outlook is bleak indeed.

I propose that close adaptation is a good alternative to translational paralysis through theoretical and agendaic moves. Close adaptation uses translation as one of its tools without having to struggle for linguistic and cultural equipments. It facilitates the forging of a suitable idiom and enables retelling through several kinds of transcendence. In Act II Scene 1 of Kanyasulkam, Gurazada gets Girisam and Venkatesam to 'converse' in English for the benefit of Venkatesam's doting, illiterate mother Venkamma. The farce enacted there is a betrayal of the first order on a trusting mother. But Gurazada immortalizes Milton's already deathless utterance by a clever act of cultural substitution amounting to a sledgehammer stroke in the course of that conversation: 'Of Man's first disobedience and the fruit of that mango tree, sing Venkatesa, my very good boy' (Apparao 1997: 43; emphasis added). The satirical punch of mango substituting for 'forbidden' from Paradise Lost, Bk. I in the farcical allusion is only one dramatic aspect of postcolonial subversion-had the colonial rulers held him answerable to questions of religious and literary blasphemy, Gurazada could comfortably have got out of a spot of bother by pleading 'ignorance' of the great literary tradition, or perhaps even an innocent slip. 
For me, Gurazada's 'fruit of that mango tree' is a cultural move that could show the way forward for a viable, creative adaptation. Such adaptation might, in turn, engender a culturally more purposeful critical review than the eulogy of the 'original' text which passes for translation-review today. 'Fruit of that mango tree' comes much closer to the Telugu culture, indeed most Indian cultures, than 'fruit of that forbidden tree' which negates the desirability of any fruit-bearing tree. This cultural desirability transcends linguistic untranslatability and moves towards cultural adaptation. Vijayasree and Vijaykumar, for instance, manage 'broomance', for 'cheepurukatta' (broom) 'sarasam' (romantic playfulness). Where plausible equivalents-standard, idiomatic, dialectal, colloquial, culturally accessible, technical, etc. constitute the domain of the inaccessible, adaptation enables the bilingual project while 'translation' can only impede it (this is best illustrated by the painstaking efforts of state-sponsored language academies, and the ludicrous results of their efforts). The mango-tree is, for me, as much a symbol of cultural adaptation and subaltern rejection/revolt, as an invitation to the reviewer-critic to delve into the complex process unfettered by rigid, deterministic presumptions. The immense flexibility offered to the reviewer-critic is productive of mature study rather than childish tiltingat-windmills which is in practice now. In turn, such review will encourage more multi-lingual literary effort. The fruit of the mango is irresistibly sweet and is an assurance against the 'forbidden' and exclusionist as in Pennepalli's principles.

\section{References}

Apparao, Gurajada (1997) Kanyasulkam, Vijayawada: EMESCO.

Rao, Velcheru Narayana (2005) God on the Hill, New Delhi: OUP.

Vijayasree, C. et.al (eds) (2007) Nation in Imagination, Hyderabad: Orient Longman. 